Научная статья

УДК 330.123.6

DOI 10.18101/2304-4446-2021-3-34-39

\title{
ЦИФРОВАЯ КУЛЬТУРА СОВРЕМЕННОГО ОБЩЕСТВА
}

\section{(C) Булгатова Юлия Сергеевна}

кандидат философских наук, доцент

feu2001@mail.ru

\section{(C) Мункуев Эрдэм Дандарович}

обучающийся

Munkuev29@mail.ru

\section{(C) Игумнова Анна Сергеевна}

обучающийся

a.igum216@mail.ru

Бурятский государственный университет имени Доржи Банзарова Россия, 670000, г. Улан-Удэ, ул. Смолина, 24а

Аннотация. В статье рассматриваются актуальные вопросы обучения цифровой культуре всех граждан общества. Определяющим для развития государства становится уровень цифровой культуры как общества, так и личности. Информация становится важнейшей составляющей социума, при этом информационно-коммуникационные технологии определяются как основа всевозможных видов деятельности по причине высокой эффективности цифровых решений. В будущем ключевое значение будут иметь такие инновации, как интернет вещей, блокчейн и т. д. Поэтому обоснована необходимость формирования цифровой компетенции. Рассмотрены понятия «Data Science», «машинное обучение», «мем». Все чаще можно услышать о появлении новой культуры цифрового общества, которая неизбежно станет важной частью общей человеческой культуры. Совершенствование структуры социума и межсоциальных взаимодействий, в составе которых особенно значимая роль отводится цифровому развитию, обусловливает появление нового типа экономической реальности.

Ключевые слова: цифровая культура, цифровые компетенции, данные, информационные системы, коммуникации

\section{Для цитирования}

Булгатова Ю. С., Мункуев Э. Д., Игумнова А. С. Цифровая культура современного общества // Вестник Бурятского государственного университета. Экономика и менеджмент. 2021. № 3. С. 34-39.

Нынешняя эпоха развития общества характеризуется повсеместной цифровизацией практически каждой сферы жизнедеятельности человека [7]. В имеющихся условиях мирового прогресса и глобализации значимость информации возрастает многократно, она становится ключевым ресурсом социума, при этом информационное обеспечение определяется как основа всевозможных видов деятельности по причине очевидной эффективности цифровых решений [6]. 
Ю. С. Булгатова, Э. Д. Мункуев, А. С. Игумнова. Цифровая культура современного общества

Все чаще можно услышать о появлении новой культуры цифрового общества, которая неизбежно станет важной частью общей человеческой культуры [5]. Степень того, насколько развита страна, все чаще соотносится с объемами и качеством информационного развития, а также разнообразием способов имплементации технологических достижений. В рамках информационных ресурсов следует отметить следующие составляющие: архивы электронных библиотек, разнообразные базы данных, каталоги и регистры, кадастровые сведения, электронные издания и прочие информационные решения. Большие массивы данных лежат в основе крупных субъектов деятельности, сюда же можно отнести и целые государства [2].

Согласно программе «Цифровая экономика Российской Федерации», утвержденной Правительством РФ 28 июля 2017 г., термин «цифровая экономика» определяется следующим образом: «это хозяйственная деятельность, ключевым фактором производства в которой являются данные в цифровой форме, что способствует формированию информационного пространства с учетом потребностей граждан и общества в получении качественных и достоверных сведений, развитию информационной инфраструктуры Российской Федерации, созданию и применению российских информационно-телекоммуникационных технологий, а также формированию новой технологической основы для социальной и экономической сферы».

В то время как непрерывные процессы развития цифровой экономики охватывают все большие территории земного шара, в странах, где цифровые решения стали необходимой реальностью, необходимо обращать внимание на должный уровень цифровой культуры населения.

Цифровая культура - это прежде всего осознание возможностей современного информационного комплекса технологий, их функциональной составляющей, а также понимание способов грамотного применения данных решений в повседневной реальности. Это имеет отношение не только к смартфонам или «умной» технике, а прежде всего к таким проявлениям, как обработка больших данных, машинное обучение, моделирование, анализ статистического характера, графическая редакция и т. д. [4].

Цифровая культура социума должна основываться на концепции фундаментальности, которая формирует ключевые компетенции, обладание которыми станет необходимостью для всех членов современного общества.

Профессионал, владеющий арсеналом навыков и умений в сфере цифровой культуры, понимает способы применения информационных инструментов, даже без специализированного образования в сфере ИТ. Помимо всего прочего, цифровая культура подразумевает соблюдение общепринятой цифровой этики, которая касается вопросов приватности информации, степени публичности данных, уровня безопасности и защищенности информации степени законодательного регулирования информационной сферы. Другими словами, культурный человек в цифровом аспекте надлежащим образом позиционирует себя в пространстве информации, осознает наличие границ дозволенного и думает о других пользователях.

Обладание знаниями в сфере культуры цифрового развития становится безусловной необходимостью, потому что технологии информационной среды распространяются среди всех сфер деятельности члена современного общества. В будущем ключевое значение будут иметь такие инновации, как интернет ве- 
щей, блокчейн, распределение сетей, автоматизация работы и робототехника. Объемы информации возрастают, их обработка способствует формированию эффективных социальных платформ, имплементации цифровизации в промышленность, образование и управление. Специалисты в больших данных и системном анализе становятся востребованными, все больше людей осознают это.

Чтобы всесторонне исследовать проявления цифровой культуры, необходимо рассмотреть наиболее характерные и часто упоминаемые результаты цифрового развития [8].

Выявление сущности понятия «Data science» не представляется простой задачей ввиду большого количества смысловых составляющих. Это область науки, где основой являются данные, а задачей - извлечение полезной информации, закономерностей и структуры данных. Однако данный термин не является полноценным без упоминания статистической составляющей.

Впервые понятие «Data science» было упомянуто в конце 1970-х гг., в тот момент, когда возможности компьютеров стремительно возросли и появился шанс скооперировать методы вычислительных процессов и инструменты статистики.

Нужно особо отметить, что эксперт в области больших данных (так называемые «data scientist») в ходе своей работы должен использовать статистические методы. Помимо статистических компетенций данный специалист должен обладать навыками программирования и специализированными знаниями в изучаемой области. Поле деятельности специалиста достаточно широко, его компетенции являются полезными для работы большинства крупных организаций [1].

Для полноценного понимания методов работы «Data science» необходимо разбираться в области машинного обучения. Этот раздел информатики касается способов разработки алгоритмов, имеющих возможность обучения. Иными словами, продукты машинного обучения во многом способны развиваться самостоятельно. Машинное обучение имеет широкое поле применения: составление и расчет прогнозов, вычисление вероятностей, составление порядка документов, оптимизация поисковиков, построение классификаций и многое другое. Выходит, что машинное обучение предоставляет подгонку данных, имеющихся у пользователя. Чаще всего точность работы продуктов машинного обучения зависит от большого числа переменных.

K примеру, в банковском деле «Data science» играют важную роль, так как процесс оценки платежеспособности клиента является ключевым для банка в ходе принятия решения о кредитовании. Для оценки применяются сведения о трудовом положении заемщика, семейном статусе, возрасте и т. д. Наука о данных имеет множественное применение в самых разных областях деятельности общества, где необходимы алгоритмы «Data science».

Кроме того, нельзя не отметить такое интернет-явление, как «мем», которое является неотъемлемой частью интернет-культуры. Мемы представляют собой сложное и комплексное культурное явление, изучать их непросто во многом изза их свойств. Мемы, по мнению Ричарда Докинза, проявляются как единицы культурной информации, способные к мутации, естественному отбору и группировке. Мемы в разрезе интернет-сферы - это информационный объект, имеющий тенденцию к росту популярности [3].

Мемы обладают некоторыми характерными чертами, например, они носят юмористический оттенок, являются актуальными, зачастую носят вирусный ха- 
Ю. С. Булгатова, Э. Д. Мункуев, А. С. Игумнова. Цифровая культура современного общества

рактер и имеют абсурдное содержание. Однако это лишь минимально необходимый набор особенностей. Установить четкие границы того, что мы называем мемом, не представляется возможным в той же степени, как и выявить границы направлений поэзии. Зачастую вы понимаете, что данное явление считается мемом, когда вы его видите. Мем обладает собственным сроком жизни. Поначалу некоторые интернет-пользователи активно обмениваются данными мемами, затем этот мем распространяется среди других пользователей, мем становится максимально популярным и вскоре постепенно забывается. Однако есть ситуации, когда мем прочно входит в плоскость языка.

Мемы проявляются по-разному: это могут быть как обычные слова, какиелибо иконки, песни, социальные посты и статьи на определённых ресурсах. В данных проявлениях часто можно встретить игру слов, культ ошибки и личностное обращение. По какой причине пользователи сети так активно применяют нелепые слова или постоянно нарушают правила грамотной речи? В соответствии с исследованиями коммуникации в интернете можно сравнить с карнавальной жизнью эпохи средневековья. Виртуальная коммуникация формирует виртуальную личность персоны, которая знает и использует правила игры. Человек не будет общаться в сети по рабочим моментам, он предпочтет использовать интернет для отдыха и игр, кроме того, он попытается обратить на себя внимание. Виртуальная персона нечасто находит выражение в реальной жизни, однако является очень креативной в интернет-сфере.

Существует ряд очень хорошо запоминающихся интернет-выражений, так как с позиции нейрофизиологии каждое явление, которое представляется нам ярким, необычным или абсурдным, проявляет у нас эмоции, что помогает максимально эффективно запоминать данные явления. Наиболее важный интерес для лингвистов в изучении интернет-культуры представляет создание новых языков. Эти языки состоят из лингвистических форм других языков, различных сокращений и интернет-терминов [9].

В настоящее время можно встретить такое явление, как общение лишь с применением интернет-выражений. Все чаще можно отметить, что в процессе какого-либо диалога, например, в комментариях к посту, люди обмениваются сообщениями вперемешку с различными мемами и гифками. Встречаются личности, которые используют лишь язык мемов для общения. Таким образом, мемы становятся неотъемлемой частью человеческой культуры, это позволяет осуществлять современные коммуникации в интернет-пространстве, во многом мемы становятся фольклорными произведениями, которые все чаще цитируются и используются.

Весомая часть коммуникаций сегодня осуществляется в интернете, причем эти коммуникации носят не только личный характер, но и деловой. Почти в каждой сфере деятельности общество сталкивается с необходимостью хранения, обработки, поиска и анализа больших массивов информации.

Чтобы максимально эффективно осуществлять данную деятельность, иными словами, максимально грамотно обращаться с окружающей нас сферой информации и в то же время иметь какие-либо полезные результаты, нужно обращаться к цифровой культуре. Тот человек, который имеет знания в этой сфере, осознает количество и качество необходимых потоков информации, какие алгоритмы соответствуют стандартам обработки и анализа данных, какие задачи представляется возможным решить, какие технологии соответствует данным задачи. 
В то же время цифровая культура в данный момент необходима практически всем профессионалам технической и гуманитарной сферы. Так как даже в случае, когда специалист не имеет обязанностей по разработке и внедрению программного обеспечения, он все ещё должен быть в состоянии ставить грамотные задачи перед программистами, надлежащим образом формулируя требования. Статистические методы и анализ больших данных обладают огромным значением во всех сферах, связанных с экономикой. Специалисты в сфере коммуникации должны обладать достаточными навыками работы с графическими редакторами, системами CMS, HTML-разметкой и другими цифровыми инструментами. Филолог должен быть в состоянии выполнить анализ текста, разбираться в биоинформатике и обработке последовательности ДНК текста. Экономика будущего заточена под цифровую экономику, это обусловливает необходимость практически всех специалистов быть в достаточной степени развитыми в плане цифровой культуры [9].

Формирование традиций цифровой культуры должно строиться на базе системного и ценностного подходов, которые коррелируют с ключевыми положениями ЮНЕСКО для общества знаний: принципы всеобщего доступа к сведениям и информации, принципы непрерывности, принципы моделирования реструктуризации обучения, принципы перспектив и комплексного подхода в обучающем процессе. Эти принципы, которые используются в совокупности, могут представлять собой основу для разработки содержательных и организационных моделей обучения, для формирования комплексной цифровой культуры современного социума.

\section{Лuтература}

1. Алексейчева Е. Ю. Актуальные подходы к формированию компетентностей будущего // Вестник Московского городского педагогического университета. Серия «Философские науки». 2020. № 1(33). С. 44-50. DOI: 10.25688/2078-9238.2020.33.1.06. Текст: непосредственный.

2. Алексейчева Е. Ю. Проблемы использования технологий информатизации в образовании // Новое в науке и образовании: сборник трудов международной ежегодной научно-практической конференции / ответственный редактор Ю. Н. Кондракова. Москва: Макс Пресс, 2018. С. 15-22. Текст: непосредственный.

3. Алексейчева Е. Ю., Скубрий Е. В., Черкашин О. Ю. Образование: показатели оценки и вопросы его совершенствования в целях развития инновационной экономики // Вестник Московского городского педагогического университета. Сер. Экономика. 2019. № 1(19). C. 99-110. DOI: 10.25688/2312-6647.2019.19.1.09. Текст: непосредственный.

4. Берман Н. Д. К вопросу о цифровой грамотности // Современные исследования социальных проблем. 2017. Т. 8, № 6-2. С. 35-38. Текст: непосредственный.

5. Булгатова Ю. С., Дырхеев А. В. Информационные технологии как средство модернизации государственного управления в современном обществе // Вестник Бурятского государственного университета. Экономика и менеджмент. 2018. № 1. С. 8-15. Текст: непосредственный.

6. Булгатова Ю. С., Сандакова Л. Г., Цыренов Д. Д. Информационные технологии в управлении деятельностью бизнес-систем в условиях трансформации российского общества. Улан-Удэ, 2016. 136 с. Текст: непосредственный.

7. Лосева А. Ю., Цыренов Д. Д. Современные информационные системы: теория и практика. Москва, 2018. 102 с. Текст: непосредственный.

8. Нехорошева Е. В. Применение сетецентрического подхода в образовании в целях формирования навыков будущего // Вестник Московского городского педагогического 
Ю. С. Булгатова, Э. Д. Мункуев, А. С. Игумнова. Цифровая культура современного общества

университета. Сер. Философские науки. 2020. № 1(33). С. 58-65. Текст: непосредственный.

9. Шаухалова Р. А. Принципы формирования цифровой культуры студентов в университете // Педагогический журнал. 2020. Т. 10, № 1А. С. 436-443. DOI: 10.34670/AR.2020.1.46.167. Текст: непосредственный.

Статья поступила в редакиию 13.07.2021; одобрена после рецензирования 30.07.2021; принята к публикации 18.08.2021.

\section{DIGITAL CULTURE OF CONTEMPORARY SOCIETY}

Yulia S. Bulgatova

Cand. Sci. (Philos.), A/Prof.

feu2001@mail.ru

Erdem D. Munkuev

Student

munkuev29@mail.ru

Anna S. Igumnova

Student

a.igum216@mail.ru

Dorzhi Banzarov Buryat State University

24a Smolina St., Ulan-Ude 670000, Russia

Abstract. The article raises the topical issues of teaching digital culture to all members of society. The level of digital culture of society, as well as personal digital culture, becomes decisive for the development of the state. Information is becoming an important component of society, while information and communication technologies are defined as a basis for all kinds of activities due to the high efficiency of digital solutions. In the future, innovations such as the Internet of Things, blockchain, etc. will be of key importance. So, it is substantiated the need for the development of digital competencies. We have considered such concepts as "Data Science", "computer-assisted teaching", "meme". New culture of a digital society will inevitably become an important part of human culture. Improving the structure of society and inter-social interactions, in which digital development plays a particularly significant role, leads to the emergence of a new type of economic reality.

Keywords: digital culture, digital competencies, data, information systems, communications

For citation

Bulgatova Yu. S., Munkuev E. D., Igumnova A. S. Digital Culture of Contemporary Society. Bulletin of Buryat State University. Economy and Management. 2021; 3: 34-39 (In Russ.).

The article was submitted 13.07.2021; approved after reviewing 30.07.2021; accepted for publication 18.08.2021. 